\title{
Obviousness around the clock
}

\section{Yves Breitmoser ${ }^{1} \cdot$ Sebastian Schweighofer-Kodritsch ${ }^{2}$}

Received: 16 May 2020 / Revised: 28 April 2021 / Accepted: 3 May 2021 /

Published online: 27 May 2021

(c) The Author(s) 2021

\begin{abstract}
Li (Am Econ Rev 107(11):3257-3287, 2017) introduces a theoretical notion of obviousness of a dominant strategy, to be used as a refinement in mechanism design. This notion is supported by experimental evidence that bidding is closer to dominance in the dynamic ascending-clock auction than the static second-price auction (private values), noting that dominance is theoretically obvious in the former but not the latter. We replicate his experimental study and add three intermediate auction formats that decompose the designs' differences to quantify the cumulative effects of (1) simply seeing an ascending-price clock (after bid submission), (2) bidding dynamically on the clock, and (3) getting (theoretically irrelevant) drop-out information about other bidders. The theory predicts dominance to become obvious through (2), dynamic bidding. We find no significant behavioral effect of (2), however, while the feedback effects (1) and (3) are highly significant. We conclude that behavioral differences between second-price and ascending-clock auctions offer rather limited support for the theory of obviousness and that framing has surprisingly large potential in mechanism design.
\end{abstract}

Keywords Experiments · Private value auctions $\cdot$ Strategy-proofness $\cdot$ Obviousness

JEL Classification C91 · D44 · D82

\section{Introduction}

Strategy-proof (SP) mechanisms offer participants a simple solution: a dominant strategy. By design, such mechanisms avoid any of the widely documented mistakes due to strategic uncertainty and errors in equilibrium reasoning. Empirical studies of

Sebastian Schweighofer-Kodritsch

sebastian.kodritsch@gmail.com

1 Bielefeld University, Bielefeld, Germany

2 Wirtschaftswissenschaftliche Fakultät, Humboldt-Universität zu Berlin, Spandauer Str. 1, 10099 Berlin, Germany 
behavior in strategy-proof mechanisms nonetheless reveal systematic mistakes, i.e., deviations from the dominant strategy. For instance, Rees-Jones (2018) and Hassidim et al. (2018) provide field evidence of systematic preference mis-representation in the deferred-acceptance mechanism for the US medical residency match; in laboratory auctions, ever since the seminal work of Kagel et al. (1987), overbidding in the sealed-bid second-price auction is a well-established and robust finding. This evidence poses the important challenge of understanding how SP mechanisms can be improved to reduce such mistakes.

Li (2017) addresses this challenge by offering a theory of obviousness of dominance in extensive-form games and of strategy-proofness in mechanisms. A dominant strategy is said to be obvious if, at any decision node along its path of play, the worst outcome under this strategy is always at least as good as even the best outcome under any alternative strategy that deviates there. By its nature, this theory is not set up to explain systematic deviations from dominance, but to capture a general source of difficulty in game cognition, whereby its implementation promises to also generally enhance dominance play. A key implication of requiring obvious strategy proofness (OSP) is that this selects dynamic/indirect mechanisms, and the theory also receives empirical support by the prominent experimental finding that, with private values, ascending-clock auctions, which are OSP, produce strikingly more dominance play than sealed-bid second-price auctions, which are not OSP (see Kagel et al., 1987; Li, 2017). ${ }^{1}$

In this paper, we experimentally investigate how design actually matters for dominance play in this leading application of private-value auctions, and we quantify the extent to which this is captured by the theory of obviousness. Our starting point is the observation that the existing evidence concerns the joint effect of changing multiple design features at once, thereby conflating "feedback effects" due to presentation and information with the direct theoretical "obviousness effect" due to dynamic implementation. The comparison of ascending-clock and sealed-bid auctions is therefore hardly informative as to how design promotes dominance play, and it also constitutes only a weak test of Li's theory. Our study overcomes these limitations by disaggregating the design differences via additional, intermediate auction formats. These separate the benchmark formats' strategic properties (static v. dynamic bid elicitation) from their feedback properties (static v. dynamic bid resolution), whereby we can quantify their relative importance for behavior. In particular, we thus isolate the effect of the dynamic bid elicitation under ascending-clock auctions, which is theoretically necessary to cause dominance to become obvious. Based on our richer comparison, we find no significant behavioral effect of dynamic bidding, however; the observed behavioral differences are instead almost entirely due to theoretically irrelevant differences in "feedback design." These results are corroborated

\footnotetext{
1 Dreyfuss et al. (2019) explain the observed dominated choices under deferred-acceptance mechanisms with expectations-based loss aversion. For auctions, von Wangenheim (2017) theoretically shows that this can also explain the comparative static of lower bidding under the ascending-clock than the sealedbid second-price auction, but not both truthful bidding under the former and overbidding under the latter format.
} 
by our structural analysis of bidding behavior, which also provides deeper insights into the cognitive channels through which feedback systematically affects mistakes.

Our experiment uses the well-documented online materials accompanying $\mathrm{Li}$ (2017) to replicate his high-powered experimental comparison of the sealed-bid second-price auction (2P) and the ascending-clock auction (AC) with the same sets of (private) valuation draws. Our innovation is the introduction of three novel auction formats to decompose the overall difference between $2 \mathrm{P}$ and $\mathrm{AC}$ into the contributions of three key design steps: clock presentation (bidders watch an ascending price clock resolve the bidding), dynamic bidding (bidders bid live on the clock), and drop-out information (bidders observe the number of opponents still bidding on the clock).

Figure 1 offers a quick overview of our experimental design and decomposition results. The novel auction formats are AC-B, 2PAC and 2PAC-B. AC-B is an ascending-clock auction just like $\mathrm{AC}$, except that it is "blinded," so that bidders do not observe their opponents' dropping out. Given private valuations, this information is theoretically irrelevant, and AC-B is also OSP. Nonetheless, the bidders' ability to condition on this information under $\mathrm{AC}$ implies that $\mathrm{AC}$ is not strategically equivalent to $2 \mathrm{P}$, so the behavioral comparison of these two formats suffers from a potential confound, which our additional comparison of $\mathrm{AC}-\mathrm{B}$ and $\mathrm{AC}$ isolates. $^{2}$ 2PAC and 2PAC-B both have bidders submit sealed bids just like 2P. However, these bids serve as automatic exit prices in a subsequently run ascending-clock auction, similar to "proxy bidding" introduced by eBay (e.g., Roth \& Ockenfels, 2002),

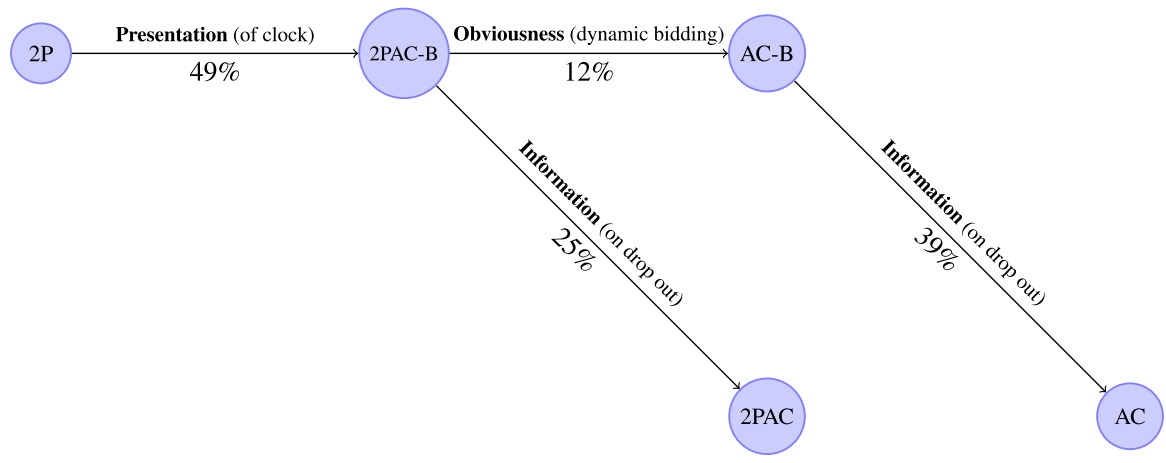

Fig. 1 Overview of auction formats analyzed in the experiment and their contributions to reduction in mean absolute deviations from truthful bidding. Note: The decomposition of the total effect reported here is derived from the decomposition of the mean absolute deviation of bids from values when we move from second-price auctions (2P) to ascending-clock auctions (AC). Specifically, using the "standardized" mean absolute deviations as reported in Table 5 (Appendix B), the presentation effect is the average effect of moving from $2 \mathrm{P}$ to $2 \mathrm{PAC}-\mathrm{B}$ after the first three auction rounds, and all other values are similarly derived, by moving from $2 \mathrm{PAC}-\mathrm{B}$ via $2 \mathrm{PAC}$ or AC-B, respectively, to AC

\footnotetext{
${ }^{2}$ When including live drop-out information, the ascending-clock auction does not have the same reduced normal form as $2 \mathrm{P}$ (see Sect. 2.3). In this sense, it should be considered as changing the strategic properties of the game. While some authors have previously pointed at its potential importance for behavior (Kagel \& Levin, 2009), it has not been systematically studied, let alone quantified.
} 
which is displayed either with drop-out information as in AC or blinded as in AC-B. Since bidders then cannot act anymore, these merely present the auction's outcome the same way as the dynamic ascending-clock formats, in terms of feedback; indeed, 2PAC and 2PAC-B are both formally identical to $2 \mathrm{P}$ and accordingly SP but not OSP. Importantly, moving from $2 \mathrm{P}$ to $2 \mathrm{PAC}-\mathrm{B}$ isolates the effect of mere clock presentation, and then moving from 2PAC-B to AC-B isolates the effect of dynamic bidding. This latter step is here in fact necessary and sufficient for theoretical obviousness of dominance, whereby the comparison of 2PAC-B and AC-B affords a both cleaner and stronger test of the prediction that OSP reliably reduces mistakes. 2PAC, by comparison with $2 \mathrm{PAC}-\mathrm{B}$, allows us to also measure the role of drop-out information as part of the passive clock-presentation, where, in contrast to AC, bidders cannot respond to it live. This summarizes what we consider the most informative comparisons. However, we can also test the basic theoretical prediction that either OSP format significantly outperforms any of the mere SP formats in terms of dominance play, where the latter include $2 \mathrm{PAC}$, of course.

Reassuringly, we find that our $2 \mathrm{P}$ and $\mathrm{AC}$ replicate the respective behavior in Li's study almost exactly. Following his analysis, we focus on mean absolute deviations from truthful bidding for non-winning bids. We find that, after a brief initial phase of around three auction rounds, where participants underbid severely in all formats (as observed also by Noussair et al., 2004, and, of course, Li, 2017; see also Cason $\&$ Plott, 2014), the relative contributions stabilize: Clock-presentation (2P $\rightarrow$ 2PAC$\mathrm{B})$ accounts for around $50 \%$ in reducing deviations from truthful bidding, dynamic bidding (2PAC-B $\rightarrow$ AC-B) promotes this further by $12 \%$, which is statistically insignificant, and the remaining share of almost $40 \%$ is due to live drop-out information $(\mathrm{AC}-\mathrm{B} \rightarrow \mathrm{AC})$. Even as pure feedback, drop-out information reduces deviations further, by $25 \%$ (2PAC-B $\rightarrow$ 2PAC), which is twice the effect of dynamic bidding.

Theoretical obviousness therefore fails our stronger test with minimally experienced participants. The live drop-out information under AC turns out to be a highly relevant design element and confound of OSP in prior evidence. Once this confound is removed, however, the entire benefit of the dynamic ascending-clock format (OSP) boils down to the effect of clock-presentation alone, as in AC-B v. 2PAC-B. Actual dynamic implementation, though theoretically required for obviousness, has no significant further benefit.

What about initial behavior? As indicated, in the very first auction rounds, participants underbid severely across all auction formats, including 2P. Here, both OSP formats very significantly reduce this underbidding mistake compared to the three non-OSP ones. ${ }^{3}$ This success of the theory regarding initial play is remarkable, but has to face the concern that dynamic auctions may be more familiar. Indeed, our

\footnotetext{
${ }^{3}$ First-round behavior is indistinguishable for both $\mathrm{AC}$ and $\mathrm{AC}-\mathrm{B}$ on the one hand, and 2P, 2PAC and 2PAC-B on the other hand, so there was no "instruction effect" in our additional treatments (see Appen$\operatorname{dix} \mathrm{C})$.
} 
evidence following initial play indicates that small differences in familiarity might produce strong behavioral effects, because minimal experience certainly does so: Deviations from dominance play generally drop sharply immediately after the first round, and both $2 \mathrm{PAC}$ and $2 \mathrm{PAC}-\mathrm{B}$ more than catch up with initial play under $\mathrm{AC}$ and $\mathrm{AC}-\mathrm{B}$ already by round 2 ; one round later even $2 \mathrm{P}$ does so weakly. This confirms our earlier conclusion that the key towards dominance is the clock presentation, which the OSP formats have before the very first bid, not the way bids are strategically elicited.

$\mathrm{Li}$ also recognizes the concern of differences in familiarity, and he addresses it by additionally running "X-auctions," which perturb the standard formats by a random mark-up element to remove any familiarity. We also include X-auctions in our study, and for these presumably unfamiliar auctions, we find no advantage to OSP even in initial play. ${ }^{4}$

Finally, we move beyond the purely descriptive analysis, to gain a deeper understanding of how design drives behavior via game cognition and monetary incentives. We analyze a structural bidding model that allows for different decision processes and operationalizes obviousness as additional decision weight on the dominant strategy beyond expected payoffs. This delivers the following insights: ${ }^{5}$ First, bidding behavior is well-explained by the actual monetary incentives that the bidders face (see also Harrison, 1989). Second, the effect of clock-presentation is to change how bidders process these incentives (expected payoffs), from a static evaluation of all possible bids at once under $2 \mathrm{P}$, to a dynamic evaluation of iteratively deciding whether to continue to increment the bid or stopping; indeed, it occurs under all formats involving clock-presentation, even the strategically static 2PAC-B and 2PAC. In contrast to static evaluation, dynamic evaluation "mechanically" entails a tendency towards some underbidding, since incentives to further increment the bid vanish when approaching one's valuation. Third, however, bidders also quickly recognize that underbidding is dominated, whereas they do not recognize this for overbidding. Moreover, the only significant difference in such obviousness is that they recognize this more strongly under AC than the other formats in standard auctions (and only there). Hence, the static decision process under $2 \mathrm{P}$ leads to overbidding, clock presentation reduces this mistake by changing game cognition to the dynamic decision process, and the ability to condition their bid on how many others are still in the auction under AC mitigates the resulting tendency to make underbidding mistakes.

OSP ties the cognitively effective clock presentation to the requirement that bids are elicited in an indirect, dynamic manner. We consider our main finding that, rather fortunately, the latter is unnecessary. This seems like a subtle distinction in theory, but given the constraints in real-world settings (e.g., global online marketplaces), it is a potentially very useful one in practical design problems. It also relates

\footnotetext{
4 As in Li's experiment, X-auctions follow the above standard auctions, always for the same format. Hence, the design we replicate is not really well-suited to address the concern.

5 These concern behavior after the first three rounds. Initial behavior bears no significant correlation with monetary incentives in any format.
} 
to the apparent success of OSP regarding initial play, since initial behavior is always preceded by a cognitive stage (in fact, a cognitive biography) that may well include opportunities for pre-play learning (e.g., dry runs against robots) provided by the designer. Moreover, this result bears good news also for the practice of experimental economics: Li's theory fundamentally challenges the widely used strategy method by predicting that it would render dominance non-obvious and introduce mistakes. Our finding that this prediction fails therefore supports the method's validity, in line with the survey of experimental comparisons by Brandts and Charness (2011).

Methodologically, our main innovation is to experimentally separate the feedback design (in particular, its framing) from the strategic design of a game, which we consider a generally promising approach for obtaining structural insights into game cognition. In doing so, we also contribute a quantification of the long suspected behavioral importance of theoretically irrelevant live drop-out information in the ascending-clock auction. Its large effect calls for caution in testing theories of game cognition such as Li's theory of obviousness: To be most informative, such tests should compare only strategically equivalent mechanisms.

Related literature The auctions we consider are mechanisms to allocate a single indivisible object among a set of agents with private valuations. This economic problem is both practically important and particularly suitable for testing OSP, as Li's Theorem 3 characterizes the class of OSP mechanisms for precisely this allocation problem: Essentially, given quasi-linear preferences, all OSP mechanisms take the form of an ascending-clock auction.

More broadly, Li provides a formal argument speaking to the larger literature suggesting that indirect implementations often have the advantage of being simpler for participants than direct ones (see, e.g., Ausubel, 2004, or Kagel \& Levin, 2009, for the case of auctions). ${ }^{6}$ The OSP requirement is supposed to circumvent cognitive limitations in contingent reasoning about hypothetical scenarios, which itself is a well-established phenomenon (Charness \& Levin, 2009; Esponda \& Vespa, 2014), though it may alternatively relate to violations of Savage's "sure-thing-principle" (Esponda \& Vespa, 2019; Martínez-Marquina et al., 2019). ${ }^{7}$

Kagel et al. (1987) were the first to demonstrate that the ascending-clock auction outperforms the sealed-bid second-price auction in terms of dominance play. Li replicated their experiment with substantially enhanced statistical power and confirmed the results. Harstad (2000) found that prior experience with the ascendingclock auction partially carries over to sealed-bid auctions. He also investigated socalled "p-list" auctions: Bidders face an ordered list of prices and indicate which are acceptable/unacceptable, and their highest acceptable price serves as bid in a second-price auction. This sealed-bid design generated underbidding, with great

\footnotetext{
${ }^{6}$ See Pycia and Troyan (2019) for a recent generalization of Li's theoretical approach, and Glazer and Rubinstein (1996) for closely related prior theoretical work.

7 Zhang and Levin (2017) show how obvious dominance has a formal interpretation in terms of preferences.
} 
variation, and experience with it was also not as helpful for the second-price auction, suggesting that it is not merely the yes/no nature of decisions in ascendingclock auctions that leads bidders to quickly adopt their dominant strategy. Kagel and Levin (2009) studied ascending-clock auctions without drop-out information, similar to our AC-B auctions, though with only 13 participants as a small add-on treatment in a study of multi-unit auctions. They already pointed to drop-out information as an important source of the greater prevalence of dominance play in the usual ascending-clock auctions, in line with our findings. Both Harstad (2000) and Kagel and Levin (2009) emphasized the general role of feedback information for whether participants recognize their dominant strategy (see also Kagel \& Levin, 2015), which our design disentangles into the effects of clock-presentation, dynamic bidding, and drop-out information.

2PAC and 2PAC-B can be seen as strategy-method implementations of an ascending-clock auction. Related to this, Schotter et al. (1994) experimentally compared behavior in simple dynamic games and their normal-form/bi-matrix versions and found strong differences. None of their games was SP, however. ${ }^{8}$ Nonetheless, in a small add-on to their baseline, where the "second" mover has a weakly dominant strategy that is obviously so only in the dynamically played version, they found that presenting the static game as though it was dynamic strongly enhances that player's dominance play. We also find a strong such presentation effect here for SP mechanisms, but we find it to work only through feedback, not instructions.

In recent complementary experimental work, Georganas et al. (2017) manipulate the losses from overbidding and show that "off-dominance" expected payoffs strongly affect behavior in 2P auctions, and McGee and Levin (2019) find that this manipulation has much smaller effects in AC auctions, showing that dominance is more obvious in the latter. Our structural analysis confirms and refines both of these observations. Schneider and Porter (2020) also document an important role of experience for dominance play in SP and OSP mechanisms, showing that it serves as a substitute for cognitive ability at the individual level. While they find that switching from $2 \mathrm{P}$ to $\mathrm{AC}$ has a larger effect than experience, we separate the strategic and the feedback experience, and we find the latter to be the main driver of dominance play.

\section{The experiment}

Our experiment exactly replicates Li's $2 \mathrm{P}$ and $\mathrm{AC}$ auctions by using the same random numbers, interface, and instructions (aside from translation). We added the three novel treatments making minimal adaptations to instructions, and excluded the third part of his experiment (random serial dictatorship mechanisms) to focus on auctions. All treatments were run strictly between subjects, using 66-72

\footnotetext{
8 They all had multiple Nash equilibria, and the differences appear due to greater use and fear of noncredible threats in the normal-form versions (see also Rapoport, 1997).
} 
participants per treatment, also similar to $\mathrm{Li}$, and all treatments were evenly allocated across time slots and weekdays within a short time span of three weeks in November and December 2017. Average payment was substantial, amounting to $€ 24$ per participant for $75-90$ min, of which $€ 5$ was a show-up fee and the remainder was the sum of profits in the experimental auctions.

\subsection{Experimental design}

The experiment consists of 20 auctions, all of which are paid. In each auction, participants bid for a money prize worth up to €130. As in $\mathrm{Li}$, individual values are affiliated by being the sum of two random draws: a group draw, which is identical for all members of a group, and a private adjustment, which is drawn independently for each individual. The group draw is uniformly distributed between $€ 10$ and $€ 110$, and the private adjustment is uniformly distributed between $€ 0$ and $€ 20$, both with a smallest monetary unit of $€ 0.25$. Before each round, participants learn their own valuations, but neither the group draw nor the private adjustment. All auctions are played anonymously in randomly matched groups of four participants. Our sessions had between 4 and 6 such groups, and we had three sessions per treatment. The treatments are as follows.

Treatment 1 (2P: Second Price) All participants submit sealed bids, between $€ 0$ and $€ 150$, in multiples of $€ 0.25$. The highest bidder wins the auction and pays the second-highest bid. No bidder wins if there is a tie for the highest bid.

Treatment 2 (AC: Ascending Clock) A price clock ticks upwards from a low starting value, in increments of $€ 0.25$, up to a potential maximum of $€ 150 .{ }^{9}$ By default, all participants are in the auction. At each price, they decide whether to irreversibly exit, the number of remaining bidders is updated and displayed on the screen. The auction ends once there is a single remaining bidder, or all remaining bidders exit simultaneously, or the maximal price is reached. If there is a single remaining bidder, she wins the auction and pays the current price. Otherwise, no bidder wins.

Following each auction, each participant observes a results summary, containing all submitted bids or exit prices, respectively, her own profit, and the winner's profit. Our additional treatments adapt the baseline auctions as follows.

Treatment 3 (2PAC: Second Price with Ascending Clock) Exactly like 2P, except that bidding is followed by an ascending-clock auction, as in AC, but where the prior bids serve as automatic exit prices and participants cannot act anymore.

\footnotetext{
9 The starting price is the highest multiple of $€ 25$ that is below the group draw.
} 
Table 1 Distribution of subjects across treatments

\begin{tabular}{lllllllll}
\hline Treatment & Number & Female & Age & GameTheo & STEM & Economics & Social sciences & Humanities \\
\hline AC & 64 & 0.72 & 21.9 & 0.28 & 0.67 & 0.45 & 0.09 & 0.16 \\
AC-B & 64 & 0.62 & 22.8 & 0.27 & 0.62 & 0.41 & 0.08 & 0.05 \\
2P & 72 & 0.54 & 23.2 & 0.19 & 0.69 & 0.50 & 0.07 & 0.11 \\
2PAC-B & 68 & 0.54 & 22.6 & 0.41 & 0.59 & 0.54 & 0.10 & 0.13 \\
2PAC & $48(+24)$ & 0.75 & 23.1 & 0.31 & 0.67 & 0.44 & 0.04 & 0.04 \\
\hline
\end{tabular}

Subjects registering to the experiment had been randomly allocated to sessions. As for 2PAC, we are missing the demographic information for one double session (with 24 subjects in total), as the ZTree server froze after running the actual experiment and prior to starting the demographics questionnaire. Owing to the random allocation to sessions, the composition of the subjects attending this session was not visibly different from that of the subjects attending the other sessions. "GameTheo" indicates the share of subjects with prior participation in classes on game theory, and the four right-most columns indicate the shares of subjects majoring in the various fields, noting that double majors mostly involve the combination of STEM and economics, and that the shares of economics students also includes students of business administration

Treatment 4 (2PAC-B: Second Price with Ascending Clock-Blind) Exactly like 2PAC, except that the clock does not display the number of remaining bidders. Instead, it always displays the total original number of bidders.

Treatment 5 (AC-B: Ascending Clock-Blind) Exactly like AC, except that the clock does not display the number of remaining bidders. Instead, it always displays the total original number of bidders.

A detailed discussion of the theoretical properties follows, but essentially, the two dynamic auctions (AC and $\mathrm{AC}-\mathrm{B}$ ) are OSP and the three static auctions (2P, 2PAC and 2PAC-B) are not OSP.

Finally, each session starts with 10 "standard auctions" as defined above, and these are followed by 10 "X-auctions." X-auctions adapt the above definitions by adding a random mark-up $X$ that is uniformly distributed between $€ 0$ and $€ 3$. It is newly drawn before each round, but not revealed to the participants until the results summary. In the $\mathrm{X}$-versions of dynamic auctions (AC and AC-B), once there is a single bidder left, the price continues to increase for another $€ X$ and stops only then; if the last remaining bidder is still in the auction, she wins the prize and pays that final clock price; otherwise, no one wins. ${ }^{10}$ In the $\mathrm{X}$-versions of the static auctions (2P, 2PAC and 2PAC-B), the highest bidder wins the prize only if her bid exceeds the second-highest bid amount by more than X; otherwise, no one wins. Following $\mathrm{Li}$ (2017), X-auctions help address potential confounds due to familiarity with particular auction designs, as none of the $\mathrm{X}$-auctions would be familiar. Since $\mathrm{X}$-auctions

\footnotetext{
${ }^{10}$ In the X-auctions of treatment $\mathrm{AC}$, once the number of remaining bidders falls to 2, the clock tells participants only that " 1 or 2 " bidders are left.
} 
always follow the standard auctions, our data on $\mathrm{X}$-auctions reflect behavior of somewhat experienced bidders.

\subsection{Logistics}

The sessions were run in November and December, 2017, at the WZB-TU lab in Berlin. Participants were recruited via ORSEE (Greiner, 2015) from a large pool of students at various universities in Berlin and distributed randomly across treatments (see Table 1 for details). ${ }^{11}$ Upon arrival at the laboratory, all participants were seated randomly by an experimental assistant at computer working places. The assistant handed out the instructions, which where then read aloud. The instructions are close translations of Li's originals, with straightforward adaptations for the novel treatments, and are provided in Appendix C. Individual questions were answered discretely. The remainder of the experiment was fully computerized using z-tree (Fischbacher, 2007); Appendix C provides screenshots. After finishing the 20 auctions, participants were paid individually by an experimental assistant in a separate room.

Besides their show-up fee of $€ 5$, participants were paid the sum of their profits from all rounds (if positive). They were paid only their show-up fee if they made an overall loss. ${ }^{12}$ The instructions contained no examples, nor was there any "dry run;" every round counted towards the total payment. The variable payoff had a wide range, from a minimum of $€ 0$ (an overall loss) to a maximum of around $€ 70$, with an average of around $€ 19$, for an average total payout of $€ 24$.

\subsection{Theoretical properties}

The theoretical background for our study basically follows from Li's theory. He proposes a formal notion of when a strategy is obviously dominant (OD), strengthening (weak) dominance and leading to his selection of obviously strategy-proof (OSP) mechanisms. Here, we briefly and informally discuss these properties, as they apply to our study, relegating formal definitions and proofs to Appendix A. There, we also explicitly deal with the discreteness of the experimental implementation, and the "X-auctions," though the logic is similar.

$2 \mathrm{P}$ and $\mathrm{AC}$ are the usual sealed-bid second-price and ascending-clock auctions, respectively. It is well-known that truthful bidding-i.e., bidding one's valuation in

\footnotetext{
${ }^{11}$ We imposed no restrictions for the lab's recruitment in terms of participants' characteristics, neither in general nor in any session, because we had no intention to investigate these. While recruitment resulted in some notable differences across different treatments' participants in terms of elicited characteristics, note that the main treatment effects concern differences in learning, and our benchmark treatments AC and $2 \mathrm{P}$ replicated behavior in Li's experiment to an enormously high degree of detail (for a quick look, see Figs. 2 and 3).

12 This payment rule with limited liability follows Li's design. Tables 5 and 6 in Appendix B provide statistics on censored and uncensored cumulative profits over rounds in all auction treatments, for our data and Li's data, respectively.
} 
$2 \mathrm{P}$, or quitting once the clock price reaches one's valuation in $\mathrm{AC}$ - is a dominant strategy in either of these auctions, hence they are strategy-proof.

OSP requires that dominance be "obvious" in the following sense: At any information set possibly reached under a player's dominant strategy, the worst possible outcome under this strategy is at least as good as the best possible outcome of any alternative strategy that deviates there. In the only information set of $2 \mathrm{P}$, the minimal payoff from truthful bidding is zero while the maximal payoff from any positive bid is one's own value. Since the former is less than the latter, truthful bidding is not OD in $2 \mathrm{P}$, violating OSP.

The dynamic AC auction meets the OSP criterion. In information sets with standing prices below one's valuation, quitting is clearly no better than truthful bidding, and when the price has reached one's valuation, staying makes a difference only in case of winning, but then comes at a loss. Thus, truthful bidding is here OD.

AC provides updated information on the number of bidders still in the auction. Given private valuations, there is nothing to learn from it, so AC-B, which suppresses it, shares the above properties with AC. In contrast to AC, however, where bidders may nonetheless condition their exit decision on the number of others remaining, the reduced normal form of AC-B actually coincides with that of $2 \mathrm{P}$ (see Thompson, 1952; Elmes \& Reny, 1994). The comparison of behavior between 2P and $\mathrm{AC}-\mathrm{B}$ rather than $\mathrm{AC}$ therefore removes possible confounds with "obviousness" that are due to this additional behavioral possibility.

$2 \mathrm{PAC}$ and $2 \mathrm{PAC}-\mathrm{B}$ both have normal forms identical to $2 \mathrm{P}$, thus sharing the aforementioned properties. They may be viewed as different presentations of $2 \mathrm{P}$, where bids unravel and feedback comes via an ascending clock. They also represent normal-form implementations of AC and AC-B, respectively, after removal of theoretically irrelevant strategies where bidders respond to opponents' dropping out. ${ }^{13}$ Either way, they introduce an ascending clock without letting bidders act in all contingencies, as OD would require, thereby allowing us to evaluate to what extent this different presentation affects behavior.

Proposition 1 In all auction formats, an agent's strategy is weakly dominant if and only if it is truthful. Whereas any truthful strategy in AC and AC-B is obviously dominant, no obviously dominant strategy exists in 2P, 2PAC or 2PAC-B. All considered auction formats are strategy-proof, whereas only $A C$ and $A C-B$ are obviously strategy-proof. All auction formats except AC have the same reduced normal form.

\footnotetext{
13 This is similar to the strategy method whose validity is surveyed by Brandts and Charness (2011); Esponda and Vespa (2019) study a related design.
} 


\section{Results}

\subsection{Deviations from truthful bidding}

Figure 2 plots the mean absolute deviations of bids from values over time, for our experiment and Li's. Initial levels are similar across all static auction formats (2P, 2PAC, 2PAC-B), 12-15 Euros, and also similar across both dynamic ones (AC, AC-B), 6-10 Euros, indicating that our additional treatments did not introduce "instruction effects," and they generally decline swiftly over the very next few rounds.

At the same time as we closely replicate Li's results on $2 \mathrm{P}$ and $\mathrm{AC}$, differences across the static and also across the dynamic formats emerge after the first two rounds. 2PAC and $2 \mathrm{PAC}-\mathrm{B}$ quickly outperform $2 \mathrm{P}$, and $\mathrm{AC}$ quickly outperforms $\mathrm{AC}-\mathrm{B}$, with all of our three novel formats (2PAC, 2PAC-B, AC-B) performing very similarly at intermediate levels from round 3 onwards.

The results indicate that subjects find the dominant strategy in AC easiest to identify. To understand the evolution of behavior, we evaluate the null hypothesis of equality of any given auction format with $\mathrm{AC}$ for six different time intervals, rounds $1-3,4-6,7-10$, which are standard auctions, and rounds 11-13, 14-16, 17-20, which are $\mathrm{X}$-auctions. We account for the panel character of the data using (twosided) tests controlling for unobserved heterogeneity, at the session level and also at the subject-level within session. Despite the large differences initially, the difference between $\mathrm{AC}$ and $2 \mathrm{PAC}$ becomes (and remains) insignificant from the final four

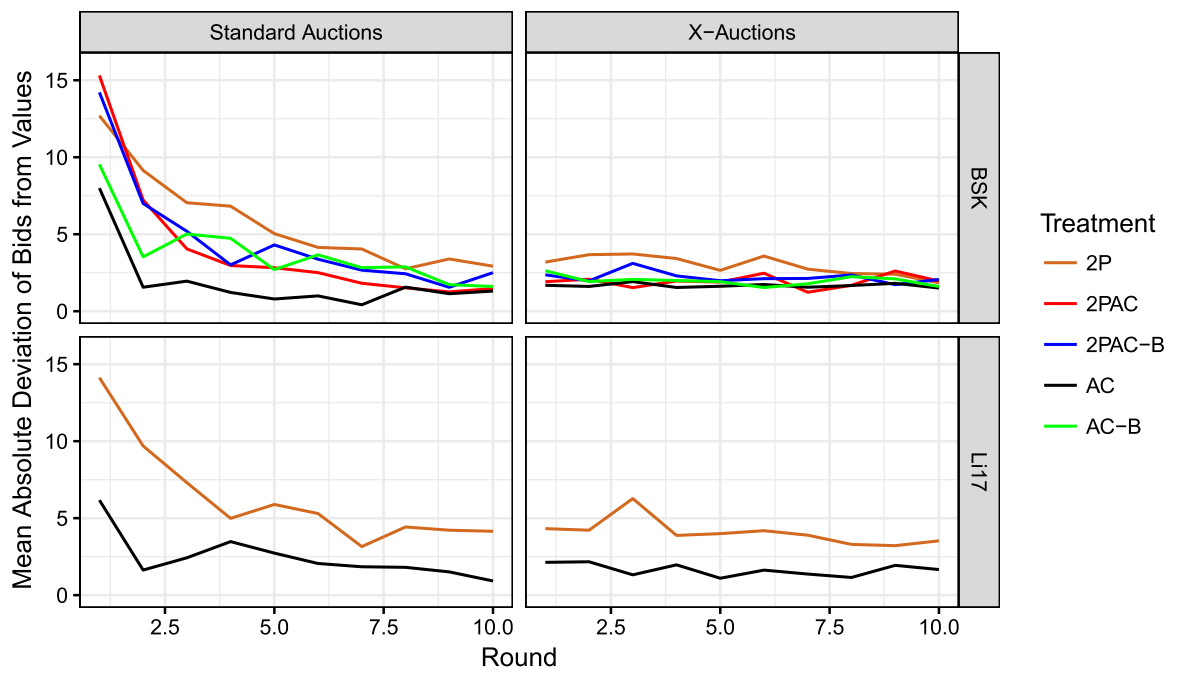

Fig. 2 Mean absolute deviations over time. Note: The plots report mean absolute deviations of bids from values for each round of the experiment, where, for comparability between static and dynamic formats (also following $\mathrm{Li}$ ), we only use non-winning bids and set all static bids below the analogous clock's starting value equal to the latter. In each of the two plots, the vertical grid lines are indicated in steps of 1.25 from 1.25 through 10 , with every other one numerically marked on the $x$-axis $(2.5,5.0,7.5,10.0)$, whereas rounds are indicated in integer steps from 1 through 10. This also applies to Fig. 4 and the plots analogous to the one here for various other measures in Appendix B 
auctions of the first stage onwards, periods $7-10$ of the standard auctions. The other auction formats catch up successively: AC-B auctions stop differing significantly from $\mathrm{AC}$ with the start of the X-auctions (periods 11-13), and the two other variants of static auctions stop differing significantly toward the end of the X-auctions (periods 17-20). The difference between plain AC and 2P auctions remains close to being significant, with a $p$ value of 0.064 in two-sided tests over the last four rounds. Hence, the contrast to Li's result-where the difference remains significant also in the final rounds of the X-auctions_-may be considered marginal (see Tables 5 and 6 in Appendix B for details).

Result 1 In all auction formats, absolute differences between bids and values decline over time, converging to small and eventually insignificantly different values.

Figure 3 shows the distributions of bids in detail, plotting histograms of the differences between bids and values. This highlights that behavior in our experiment resembles behavior in Li's at an enormous level of detail: in both $2 \mathrm{P}$ and AC auctions the initial bid distributions are virtually equivalent to Li's, and subjects initially tend to underbid in all auction formats (as in comparable experiments, e.g., Noussair et al., 2004). The tendency to overbid develops almost exclusively in $2 \mathrm{P}$, both in our experiment and in Li's. In 2P, eventually around $40 \%$ of bids exceed the respective bidders' values by more than $€ 1$ (a conventional threshold for overbidding), and in all other auction formats, this value remains below 20\%. Apparently, the simple modification of showing a passive clock after bid submission (2PAC, 2PAC-B) substantially helps subjects not to develop the tendency to overbid - even if the auction itself formally maintains sealed bids. ${ }^{14}$

Result 2 Initially, subjects tend to underbid, and only in $2 P$ auctions, subjects learn to systematically overbid. Exposing them to an ascending clock, be it actively (during bidding) or passively (after bidding), largely prevents the shift toward overbidding.

The pure presentation effect of the ascending clock concerns the difference between the classic $2 \mathrm{P}$ and the novel format $2 \mathrm{PAC}-\mathrm{B}$, and since round- 1 behavior is very similar, sharing a pronounced tendency towards underbidding, it is due exclusively to differences in learning. The effect sets in very quickly: Bidders generally bid closer to their values, but the clock presentation in 2PAC-B prevents the shift towards overbidding in $2 \mathrm{P}$ and keeps mean absolute deviations of bids from values (MADs) lower throughout. The effect is also long-lived. While differences become insignificant in terms of MADs by the final standard auction of round 10, the nature of the remaining bias is markedly different: In $2 \mathrm{P}$, there is three times more

\footnotetext{
${ }^{14}$ It is worthwhile pointing out here that average time spent per auction round in 2PAC and 2PAC-B (around $3 \mathrm{~min}$ ) is only somewhat longer than in $2 \mathrm{P}$ (around $2.5 \mathrm{~min}$ ), and that, as shown below (Table 3), the decision time taken prior to bid submission is not correlated with the deviation from truthful bidding in any of the static auction formats.
} 


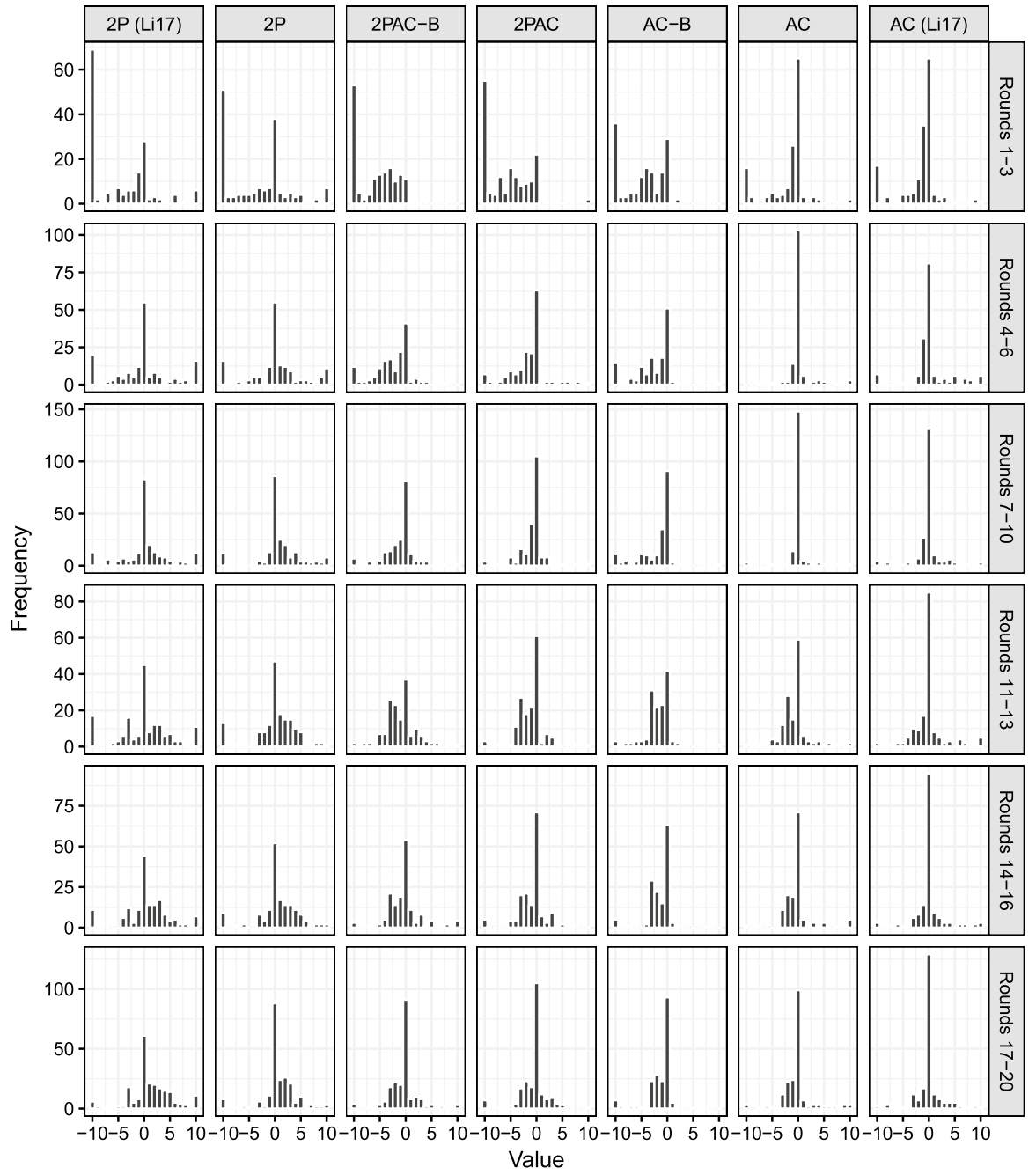

Fig. 3 Distributions of actual deviations (bid-value) over time

overbidding than underbidding, whereas in $2 \mathrm{PAC}-\mathrm{B}$ this is reversed, with roughly twice as much underbidding than overbidding (see Figures 13 and 14 in Appendix B). 
Notably, the evolution of bidding we observe under classic $2 \mathrm{P}$ (here and in Li's data) is well in line with the large number of prior experiments on this format; ${ }^{15}$ e.g., revisiting the data from the most closely related experiments of Kagel et al. (1987), Harstad (2000, p. 267) observes: “(...) subjects upon encountering a secondprice auction respond with tremendous heterogeneity, most bidding below their values initially. Bidding rapidly becomes more aggressive, quickly breaking through the threshold of bidding equal to value." Harstad also documents carry-over effects on $2 \mathrm{P}$ behavior from prior experience with $\mathrm{AC}$ or "price acceptance list" auctions, which relates well with the effect of presentation we find in comparing $2 \mathrm{P}$ with 2PAC-B.

On top of the pure effect of clock presentation, we seem to be observing a second effect due to actual dynamic bidding and a third effect due to drop-out information (equivalently, blindness). Recall that actual dynamic bidding implies OSP in our context, and thus we hypothesized an effect, whereas drop-out information is theoretically irrelevant. The pure effect of dynamic bidding on the clock concerns the difference between our two novel formats 2PAC-B and AC-B. When both are combined with drop-out information, it concerns the difference between 2PAC and AC. Figure 2 suggests that this effect is significant in round 1, while $2 \mathrm{PAC}$ and $2 \mathrm{PAC}-\mathrm{B}$ (when combined referred to as $2 \mathrm{PAC}^{*}$ ) subsequently seem to catch up with $\mathrm{AC}$ and $\mathrm{AC}-\mathrm{B}$ (when combined referred to as $\mathrm{AC}^{*}$ ), respectively. Potentially, however, learning in the $2 \mathrm{PAC}^{*}$ auctions simply is delayed by one round, i.e., it is comparable to learning in the actual dynamic auctions $\mathrm{AC}^{*}$ once we account for the mechanical one-round delay implied by displaying the clock only after bids have been submitted in the 2PAC* auctions rather than live. In Fig. 4 and Tables 2a, 2b, we have put this exploratory hypothesis to a simple test focusing on the standard auctions of rounds 1 through 10 where the main differences in learning occur. The results in Table 2a suggest that the mechanical one-round delay explains the differences between 2PAC-B and AC-B but not quite between 2PAC and AC: The effect of actual dynamic bidding ("Dynamic") becomes insignificant between 2PAC-B and AC-B when bidding in AC-B is lagged by one round, yet remains significant between $2 \mathrm{PAC}$ and $\mathrm{AC}$ with a one-round lag. Table $2 \mathrm{~b}$ shows that overall, a two-round delay captures the difference in the evolution of behavior towards truthful bidding fairly exhaustively.

Result 3 Actual dynamic bidding on the ascending clock accelerates learning to bid truthfully by approximately one round in the absence of drop-out information, and two rounds in the presence of drop-out information, as well as overall.

\footnotetext{
15 See Kagel et al. (1987), Kagel and Levin (1993), List and Shogren (1999), Harstad (2000), Cooper and Fang (2008), Andreoni et al. (2007) and Kirchkamp and Reiß (2019) for comparable experiments with sufficiently many rounds where behavior appears to converge; all of these observe initial underbidding, and so do those with only a few rounds of 2P by Güth et al. (2003), Aseff (2004), Noussair et al. (2004) and Garratt et al. (2012). The extent of initial underbidding in our experiment is relatively large, which is likely due to the fact that, in contrast to most prior work, we did not include any dry runs or quizzes or other training before the first real auction.
} 


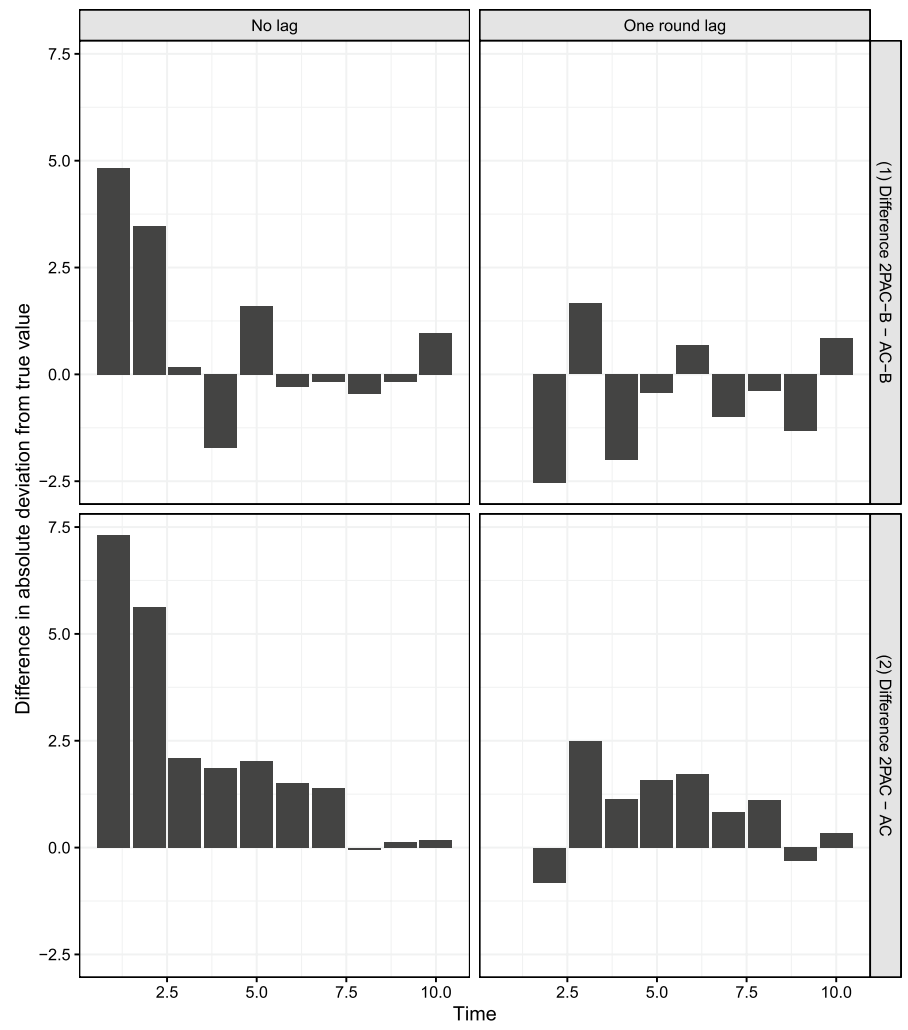

Fig. 4 Actual dynamic bidding tends to accelerate learning by at least one round. Note: The figure plots the differences in mean absolute deviations from sincere bidding (mean of absolute value of bid minus value, taken over all subjects in a given round of auctions) between (i) subjects in 2PAC-B and AC-B treatments (top panels), and (ii) subjects in 2PAC and AC treatments (bottom panels). The panels on the left-hand side display the raw differences in each round of auctions, and the panels on the right-hand side display the differences when the differences in the auctions with actual dynamic bidding (AC-B and AC) are lagged by one round-e.g. the top-right panel displays, at time $t$, the difference between the MAD from sincere bidding in 2PAC-B in round $t$ to the MAD from sincere bidding in AC-B in round $t-1$

Finally, blindness to drop-out information seems to matter by itself. As observed with Fig. 2, bidders deviate more from dominance play in AC-B than in AC. Table 2c reports on the significance of this effect of blindness ("Blind"), again focusing on the standard auctions, and demonstrates that it is indeed significant under dynamic bidding, between $\mathrm{AC}$ and $\mathrm{AC}-\mathrm{B}$, but not under static bidding, between $2 \mathrm{PAC}$ and 2PAC-B. Overall, when aggregating AC and 2PAC (denoted as *C) as well as AC-B and $2 \mathrm{PAC}-\mathrm{B}$ (denoted as ${ }^{*} \mathrm{C}-\mathrm{B}$ ), respectively, the effect is once again significant.

Result 4 Drop-out information on the ascending clock has no significant effect on truthful bidding under static bidding (passive information), whereas it significantly reduces deviations under dynamic bidding (live information) as well as overall. 
Table 2 The effects of allowing for dynamic bidding and blinding drop-out information

\begin{tabular}{|c|c|c|c|c|}
\hline & \multicolumn{2}{|c|}{ 2PAC-B vs AC-B } & \multicolumn{2}{|l|}{ 2PAC vs AC } \\
\hline & Baseline & Dyna Lag 1 & Baseline & Dyna Lag 1 \\
\hline \multicolumn{5}{|c|}{ (a) Effect of dynamic bidding by treatments } \\
\hline \multirow[t]{2}{*}{ (Intercept) } & $12.85^{* * * *}$ & $9.28 * * *$ & $12.02 * * *$ & $6.99 * * *$ \\
\hline & $(0.84)$ & $(0.82)$ & $(0.70)$ & $(0.51)$ \\
\hline \multirow[t]{2}{*}{ Period } & $-1.14 * * *$ & $-0.76^{* * *}$ & $-1.16^{* * *}$ & $-0.63 * * *$ \\
\hline & $(0.11)$ & $(0.11)$ & $(0.09)$ & $(0.06)$ \\
\hline \multirow[t]{2}{*}{ Dynamic } & $-2.81 * * *$ & -0.71 & $-3.71 * * *$ & $-1.22 *$ \\
\hline & $(0.84)$ & $(0.72)$ & $(0.71)$ & $(0.54)$ \\
\hline AIC & 7417.94 & 6369.37 & 7314.94 & 5565.65 \\
\hline $\mathrm{BIC}$ & 7442.43 & 6393.33 & 7339.57 & 5589.76 \\
\hline Log likelihood & -3703.97 & -3179.68 & -3652.47 & -2777.82 \\
\hline Num. obs. & 990 & 891 & 1020 & 918 \\
\hline Num. groups & 132 & 132 & 136 & 136 \\
\hline Var: subj & 10.13 & 6.66 & 7.79 & 6.75 \\
\hline \multirow[t]{2}{*}{ Var: Residual } & 96.56 & 68.50 & 69.69 & 20.97 \\
\hline & Baseline & Dyna Lag 1 & Dyna Lag 2 & \\
\hline
\end{tabular}

(b) Effect of dynamic bidding aggregating (2PAC-B, 2PAC) and (AC-B, AC)

\begin{tabular}{llll} 
(Intercept) & $12.40^{* * *}$ & $8.11 * * *$ & $6.54 * * *$ \\
Period & $(0.54)$ & $(0.49)$ & $(0.52)$ \\
& $-1.11^{* * *}$ & $-0.69 * * *$ & $-0.53 * * *$ \\
Dynamic & $(0.07)$ & $(0.06)$ & $(0.06)$ \\
& $-3.41 * * *$ & $-0.96^{*}$ & 0.09 \\
AIC & $(0.56)$ & $(0.46)$ & $(0.45)$ \\
BIC & 17635.94 & 12206.93 & 10454.01 \\
Log likelihood & 17664.77 & 12234.43 & 10480.92 \\
Num. obs. & -8812.97 & -6098.46 & -5222.00 \\
Num. groups & 2360 & 1809 & 1608 \\
Var: subj & 268 & 268 & 268 \\
Var: Residual & 9.95 & 7.37 & 7.67 \\
\hline & 95.29 & 44.39 & 33.57 \\
\hline
\end{tabular}

(c) Effect removing drop-out information ("blindness" of auctions)

\begin{tabular}{llll} 
(Intercept) & $14.08^{* * *}$ & $4.72 * * *$ & $10.24 * * *$ \\
Period & $(0.88)$ & $(0.43)$ & $(0.57)$ \\
& $-1.53 * * *$ & $-0.50 * * *$ & $-1.15^{* * *}$ \\
Blind & $(0.11)$ & $(0.05)$ & $(0.07)$ \\
& 1.19 & $1.80 * * *$ & $1.29 *$ \\
AIC & $(0.92)$ & $(0.44)$ & $(0.58)$ \\
BIC & 11004.24 & 5851.46 & 14783.75 \\
Log likelihood & 11030.46 & 5875.79 & 14811.78 \\
\hline
\end{tabular}


Table 2 (continued)

\begin{tabular}{llll}
\hline & 2PAC-B vs 2PAC & AC-B vs AC & $*$ C-B vs *C \\
\hline Num. obs. & 1400 & 960 & 2010 \\
Num. groups & 140 & 128 & 268 \\
Var: subj & 15.88 & 2.93 & 11.36 \\
Var: Residual & 139.91 & 23.51 & 82.98 \\
\hline
\end{tabular}

All tables present the results of regressions, with random effects at the subject level, where the dependent variable is the absolute value of the difference between bid and value of a subject. This difference is regressed on the auction being "Dynamic" or not (value 1 or 0 , respectively), or "Blind" or not (value 1 or 0 , respectively), controlling for the number of the auction within the session ("Period"). In the columns labeled "Dyna Lag $x$ ", the mean absolute deviations from dynamic auctions are lagged by $x$ rounds (see also Fig. 3). The lines labeled "Num. groups" indicate the number of subjects (with the random effect being at the subject level), "Var: subj" indicates the variance of this random effect, and "Var: Residual" indicates the variance of the residual

$* * * p<0.001 ; * * p<0.01 ; * p<0.05$

Figure 1 in the introduction summarizes our results on these effects, aggregating over all auctions following the first three rounds and decomposing the total difference in MADs between $2 \mathrm{P}$ and $\mathrm{AC}$ into the percentage contributions of clock presentation, dynamic bidding and drop-out information, respectively. Clock presentation contributes the largest share to reducing deviations from truthful bidding, whereas dynamic bidding only significantly adds to this in conjunction with (live rather than passive) drop-out information.

The effect of drop-out information we observe is puzzling. We are not aware of any theory that would generate a hypothesis as to how this effect comes about. However, since our experiment provides the first instance of a clean treatment comparison regarding such information, we add here a suggestive exploratory analysis devoted to this effect, which we hope may be picked up in future research.

In hindsight, we suspected that it would be relevant for learning dominance from seeing opponents' bids whether there are such bids near one's own value (differing by no more than two monetary units). Table 3 reports the results of a test of this post-hoc intuition, again focusing on standard auctions, and they suggest that this may indeed be important for explaining why bidding in AC is significantly closer to dominance play than in AC-B. More precisely, the indicator "prevNearMyVal" equals 1 if in the previous auction at least one opponent submitted a bid deviating from one's value (in that auction) by no more than 2 Euros. It has a rather large, negative and significant coefficient in $\mathrm{AC}$, reducing deviations from truthful bidding, but is not significant in any other auction format, including AC-B. Notably, this is also in line with Result 4, establishing the absence of a significant effect of drop-out information in the static formats 2PAC and 2PAC-B. Seeing opponents drop out near one's value therefore seems 
Table 3 Determinants of deviations from sincere bidding (BSK)

\begin{tabular}{llllll}
\hline & \multicolumn{4}{l}{ Dependent variable: Absolute value of difference between bid and value } \\
\cline { 2 - 6 } & $2 \mathrm{P}$ & 2PAC-B & 2PAC & AC & AC-B \\
\hline Intercept) & $11.50^{* * *}$ & 3.16 & $3.87^{* *}$ & $2.99^{* * *}$ & 2.11 \\
& $(3.23)$ & $(2.65)$ & $(1.24)$ & $(0.84)$ & $(1.16)$ \\
Period & $-1.15^{* * *}$ & $-0.45^{*}$ & $-0.57^{* * *}$ & -0.07 & $-0.33^{* * *}$ \\
& $(0.23)$ & $(0.21)$ & $(0.09)$ & $(0.06)$ & $(0.08)$ \\
Value & 0.03 & $0.06^{* *}$ & $0.02^{* * *}$ & 0.00 & $0.02^{* *}$ \\
& $(0.02)$ & $(0.02)$ & $(0.01)$ & $(0.01)$ & $(0.01)$ \\
DecisionTime & -0.01 & 0.01 & 0.03 & & \\
& $(0.03)$ & $(0.03)$ & $(0.02)$ & & \\
PreviousDeviation & $0.10^{* *}$ & $0.19 * * *$ & $0.08^{* * *}$ & $-0.02^{* * *}$ & -0.00 \\
& $(0.04)$ & $(0.04)$ & $(0.02)$ & $(0.01)$ & $(0.01)$ \\
prevNearMyVal & -0.64 & -2.02 & -0.34 & $-1.55^{* *}$ & 0.35 \\
& $(1.20)$ & $(1.04)$ & $(0.44)$ & $(0.52)$ & $(0.55)$ \\
prevAboveMyVal & 1.14 & -0.43 & -0.21 & 0.02 & $1.53^{*}$ \\
& $(1.28)$ & $(1.21)$ & $(0.49)$ & $(0.41)$ & $(0.72)$ \\
AIC & 3902.15 & 3468.50 & 2952.45 & 2292.59 & 2568.00 \\
BIC & 3939.82 & 3505.66 & 2990.13 & 2325.14 & 2600.55 \\
Log likelihood & -1942.07 & -1725.25 & -1467.23 & -1138.29 & -1276.00 \\
Num. obs. & 486 & 459 & 486 & 432 & 432 \\
Num. groups & 72 & 68 & 72 & 64 & 64 \\
Var: subj & 70.37 & 1.59 & 9.76 & 1.29 & 5.98 \\
Var: Residual & 138.01 & 104.84 & 19.06 & 10.00 & 17.60 \\
\hline
\end{tabular}

For each of the treatments, we regress the absolute value of the difference between bid and value on "DecisionTime" (the time taken by a subject to submit the bid in sealed bid auctions"), "prevNearMyVal" (a binary indicator equal to one if at least one of the opponents submitted a bid in the previous auction deviating from my value in that auction by no more than 2 Euro), "prevAboveMyVal" (a binary indicator equal to one if at least one of the opponents submitted a bid in the previous auction above my value in that auction by more than 2 Euro), controlling for the number of the auction within the session ("Period"), the value of the subject, and the subject's absolute value of the difference between bid and value in the previous auction ("PreviousDeviation"). As above, we allow for random effects at the subject level, where "Num. groups" indicates the number of subjects, "Var: subj" indicates the variance of the random effect, and "Var: Residual" indicates the variance of the residual

$* * * p<0.001 ; * * p<0.01 ; * p<0.05$

to trigger a better understanding of dominance when this is observed live during the actual auction, but not when observed only as feedback after bidding.

Finally, Table 3 also explores potential further determinants of deviations from truthful bidding, to round off this overview of basic results. It shows that the "Period" itself, i.e., the number of the auction within the session, seems to matter highly significantly in reducing deviations, and that the deviations tend to be auto-correlated (see the significance of "PreviousDeviation" in most treatments), while "DecisionTime" which is the time taken by subjects prior to bid 


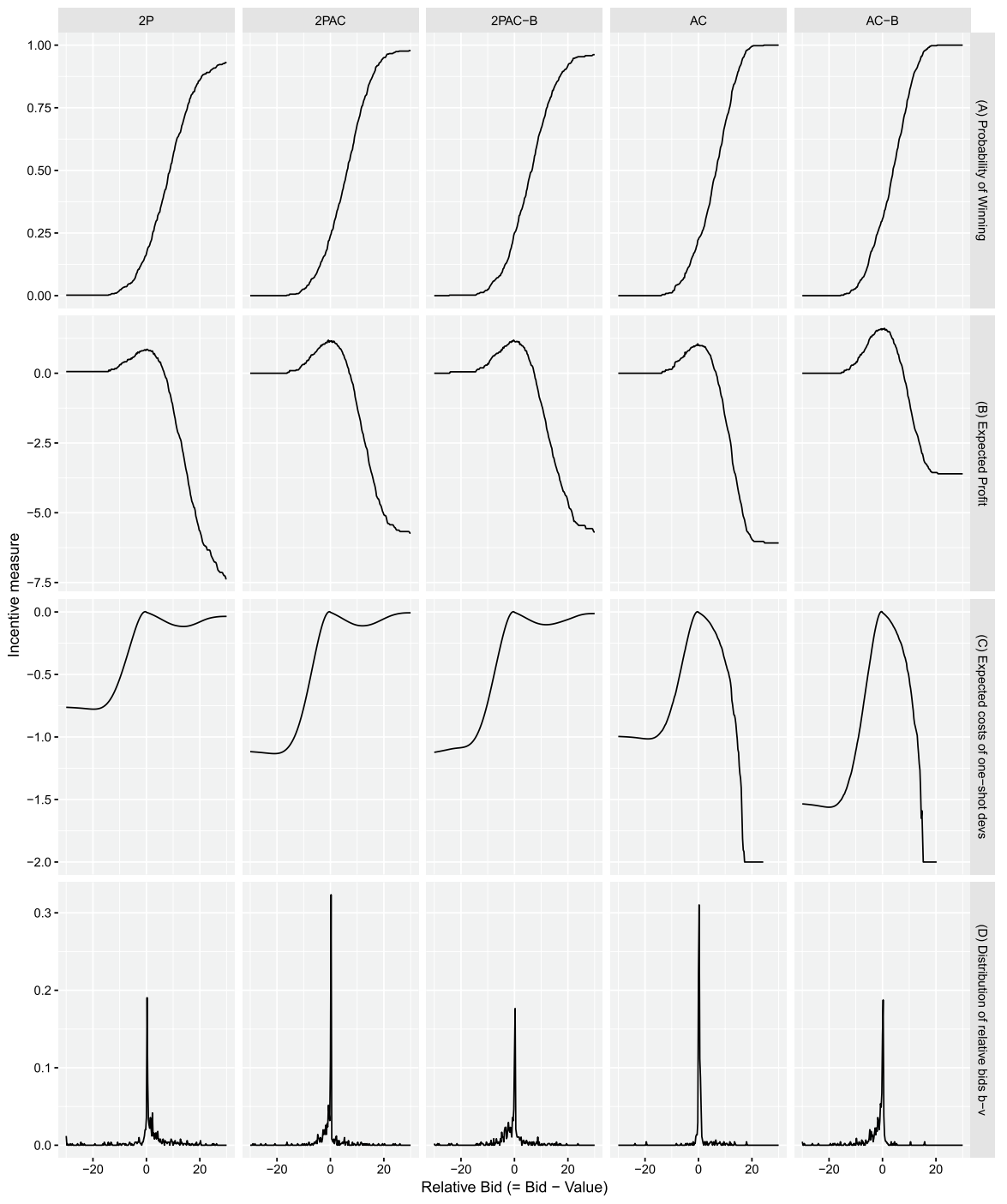

Fig. 5 Beliefs, profits and incentives under rational expectations (periods 4-10 of standard auctions)

submission in the static auctions does not directly correlate with the extent of truthful bidding.

\subsection{Economic incentives in static and dynamic auctions}

In order to better understand this observed behavior, let us relate it to economic incentives and "optimization premia" in the sense of Battalio et al. (2001). Specifically, we seek to evaluate the monetary costs associated with deviations from 
the dominant strategy, loosely following Harrison (1989), and based on this, we shall set up a simple structural model evaluating to which extent and also how subjects' behavior reflects these incentives.

Given a subject with value $v$ and any bid $b$, define the "relative bid" $a=b-v$ as the amount by which this bid exceeds the subject's value. Let $A$ denote the set of possible relative bids. The highest opponent bid is a random variable $B^{*}$, and the conditional probability that it equals $b^{*}$ is $\operatorname{Pr}\left(B^{*}=b^{*} \mid v\right)$. We make the conventional assumption that subjects abstract from distortions at the bounds of the signal space, so we can capture subjective beliefs about $B^{*}$ in terms of relative bids (i.e., independently of their own signal). Formally, a belief is then a function $\sigma_{b} \in \Delta(A)$, and $\sigma_{b}\left(a^{*}\right)$ denotes the probability that the highest relative bid of an opponent is $a^{*}$, where relative refers to $v$ (i.e., the highest actual opponent bid is $b^{*}=v+a^{*}$ ).

Expected payoffs of bids The subjective probability that bidding $a$ wins the auction is $\sum_{a^{\prime}<a} \sigma_{b}\left(a^{\prime}\right)$. The winning probabilities faced by subjects in our experiment are presented in panel (A) of Figure 5 for rounds 4-10 of the standard auctions (for further plots see Appendix B). ${ }^{16}$ For example, bidding $a=0$ yields values very close to the theoretically predicted winning probability of 0.25 in all treatments except $2 \mathrm{P}$, where it is slightly lower, at 0.19 , due to subjects' overbidding. Given belief $\sigma_{b}$, the ex-ante expectation of the profit from bidding $a$ is

$$
\Pi(a)=-\sum_{a^{\prime}<a} a^{\prime} \cdot \sigma_{b}\left(a^{\prime}\right)
$$

which, for our data, is displayed in panel (B) of Fig. 5. The (weakly) dominant strategy of bidding truthfully, $a=0$, generally maximizes expected payoffs. Close to bidding truthfully, the empirical payoffs are fairly symmetric and flat (see also Harrison, 1989; Georganas and Nagel 2011), but further away from truthful bidding, overbidding is substantially more costly than underbidding. This suggests that subjects would tend to underbid in static auctions.

Expected payoffs of bid increments In ascending-clock auctions, a subject is sequentially presented various values of $a$ as the clock ascends, starting at relatively low bids $a<0$, up to potentially high bids $a>0$. Here, we directly quantify the costs of enacting one-shot deviations from the dominant strategy. At bids $a<0$, the one-shot deviation requires the subject to stop bidding, thus forfeiting the expected profits associated with the dominant strategy. At bids $a \geq 0$, the one-shot deviation requires the subject to keep bidding for exactly one bid increment, and thus to risk winning the auction at a price above her value $v$. We denote the expected costs of such one-shot deviations, conditional on the current bid $a$, as $L_{A C}^{-}(a)$ and $L_{A C}^{+}(a)$ for the cases $a<0$ and $a \geq 0$, respectively.

\footnotetext{
${ }^{16}$ In dynamic auctions, where the winning bid was not observed, it was imputed as being equal to the maximum of the winner's value, and the highest observed bid plus 0.25 .
} 


$$
a<0: \quad L_{A C}^{-}(a)=\frac{\sum_{a^{\prime}=a}^{0} a^{\prime} \cdot \sigma_{b}\left(a^{\prime}\right)}{\sum_{a^{\prime}=a}^{\infty} \sigma_{b}\left(a^{\prime}\right)} \quad a \geq 0: \quad L_{A C}^{+}(a)=\frac{-a \cdot \sigma_{b}(a)}{\sum_{a^{\prime}=a}^{\infty} \sigma_{b}\left(a^{\prime}\right)}
$$

We can evaluate analogously such expected costs of "one-shot deviations" in static auctions. Intuitively, we will think of a subject engaging in a hypothetical thought process that mimicks the ascending clock: Starting at low bids, she iteratively evaluates whether to increment her bid or not, up to a point where she decides to stop, which yields the bid she eventually submits in the auction. Since this thought process takes place ex ante, so would be expectations, implying

$$
a<0: \quad L_{2 P}^{-}(a)=\sum_{a^{\prime}=a}^{0} a^{\prime} \cdot \sigma_{b}\left(a^{\prime}\right) \quad a \geq 0: \quad L_{2 P}^{+}(a)=-a \cdot \sigma_{b}(a) .
$$

The expected costs of deviating from the dominant strategy for our experimental subjects are provided in panel (C) of Fig. 5. The differences across treatments are striking. Ex-ante, the probability that a one-shot bid increment beyond one's value turns out costly is very low. Hence, subjects have little reason not to increment their bid by a tick when deliberating their choice based on unconditional expected costs $L_{2 P}$ in static auctions. Ex post-i.e., conditional on the standing price being above their own value - further increments likely win the auction, thereby yielding a substantial loss even in expectation and providing subjects with strong incentives to play the dominant strategy and exit. This relates closely to the intuition of Cooper and Fang (2008), that bidders perceive the benefits and costs of raising their bids differently in sealed-bid and ascending-clock auctions, and indeed clarifies that this intuition is not solely an implication of bounded rationality (as conjectured by Cooper and Fang). It represents the difference between unconditional and conditional monetary incentives.

Both unconditional and conditional expected costs are contained as special cases in

$$
L^{-}(a)=\frac{\sum_{a^{\prime}=a}^{0} a^{\prime} \cdot \sigma_{b}\left(a^{\prime}\right)}{\left(\sum_{a^{\prime}=a}^{\infty} \sigma_{b}\left(a^{\prime}\right)\right)^{\beta}} \quad L^{+}(a)=\frac{-a \cdot \sigma_{b}(a)}{\left(\sum_{a^{\prime}=a}^{\infty} \sigma_{b}\left(a^{\prime}\right)\right)^{\beta}},
$$

where the unconditional expectation obtains for $\beta=0$ and the conditional expectation obtains for $\beta=1$. Since $\beta=1$ refers to the case that subjects compute expected costs (of one-shot deviations) contingent on having reached the information set where this deviation is implemented, and $\beta=0$ refers to the case where subjects do not account for this contingency, we refer to $\beta$ as the degree of contingent reasoning. By estimating $\beta$, we will thus be able to assess if there are differences in the degree of contingent reasoning between treatments, potentially as a function of whether the auction is OSP - thus testing if obviousness amplifies contingent reasoning. 


\subsection{Analysis of behavior in relation to economic incentives}

Given the previous definitions, we can use a structural model to analyze how behavior reflects these incentives, and in particular, whether it corresponds to the static perspective in Eq. (1), the ex-post incremental perspective in Eq. (2), or the ex-ante incremental perspective in Eq. (3). Our prior hypothesis is that subjects bid according to incentives from the static perspective in static auctions and according to the ex-post incremental perspective in dynamic auctions.

In addition, our analysis of incentives allows us to examine further the cognitive channels through which theoretical obviousness (might) affect behavior. One possible channel was introduced already: it could help subjects in reasoning contingently such that they compute conditional rather than unconditional expected payoffs. Another channel might be that it heightens the perception of payoff differences across the board, which we can capture through allowing for differences in the usual precision parameter $\lambda$ below. A third, slightly more subtle but also more direct channel is that it helps subjects find the dominant action such that it is chosen disproportionately often, i.e., more often than payoff differences predict. Here, we follow Huck et al. (2015) and Breitmoser (2021), amongst others, who capture choice effects due to roundedness of numbers by allowing for additive increments to choice propensities (or, utilities) when numbers are round. If these increments are significantly positive, then the numbers are chosen more often than say utility differences predict. We will estimate similar additive increments for the dominant action, which may be considered "focal" in the sense of Breitmoser (2021), to then test for their significance and also for differences across auction formats. Our hypothesis is, naturally, that subjects react to dominance more when it is formally obvious.

Our structural model directly implements the monetary incentives quantified above assuming logistic errors. Allowing for logistic errors follows McKelvey and Palfrey $(1995,1998)$ and is standard practice in behavioral analyses of laboratory experiments (Goeree et al., 2008), in particular also in analyses of auctions (Goeree et al., 2002; Crawford \& Iriberri, 2007; Turocy, 2008). In addition to the monetary incentives, our specification will include terms $v^{-}$and $v^{+} \geq 0$ that denote the aforementioned additional weight awarded to the dominant action to continue if $a<0$ and not to continue if $a \geq 0$ (or, in static auctions, to not deviate from bidding one's value toward either $a<0$ or $a>0$, respectively). These weights capture the degree to which dominance as such is choice-relevant-beyond elevating expected payoffs.

Thus, given the current price is $a$, a subject holding the "dynamic perspective" in Eq. (4) does not exit (or, continues bidding) with probability

$$
\begin{aligned}
& a<0: \quad \operatorname{Pr}_{\text {cont }}(a)=\frac{\exp \left\{-\lambda \cdot L^{-}(a)+v^{-}\right\}}{\exp \{0\}+\exp \left\{-\lambda \cdot L^{-}(a)+v^{-}\right\}}, \\
& a \geq 0: \quad \operatorname{Pr}_{\text {cont }}(a)=\frac{\exp \left\{\lambda \cdot L^{+}(a)-v^{+}\right\}}{\exp \{0\}+\exp \left\{\lambda \cdot L^{+}(a)-v^{+}\right\}} .
\end{aligned}
$$




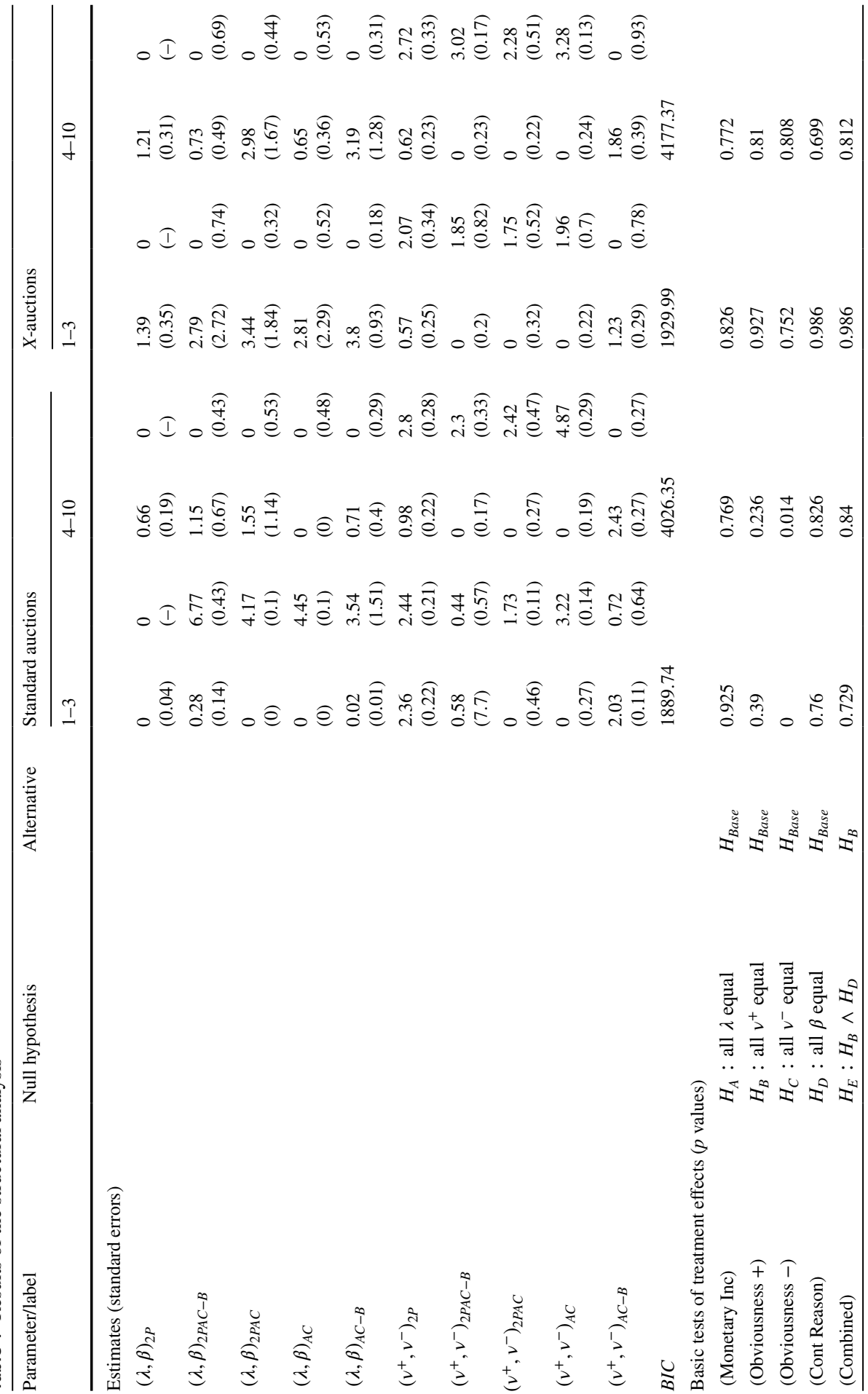




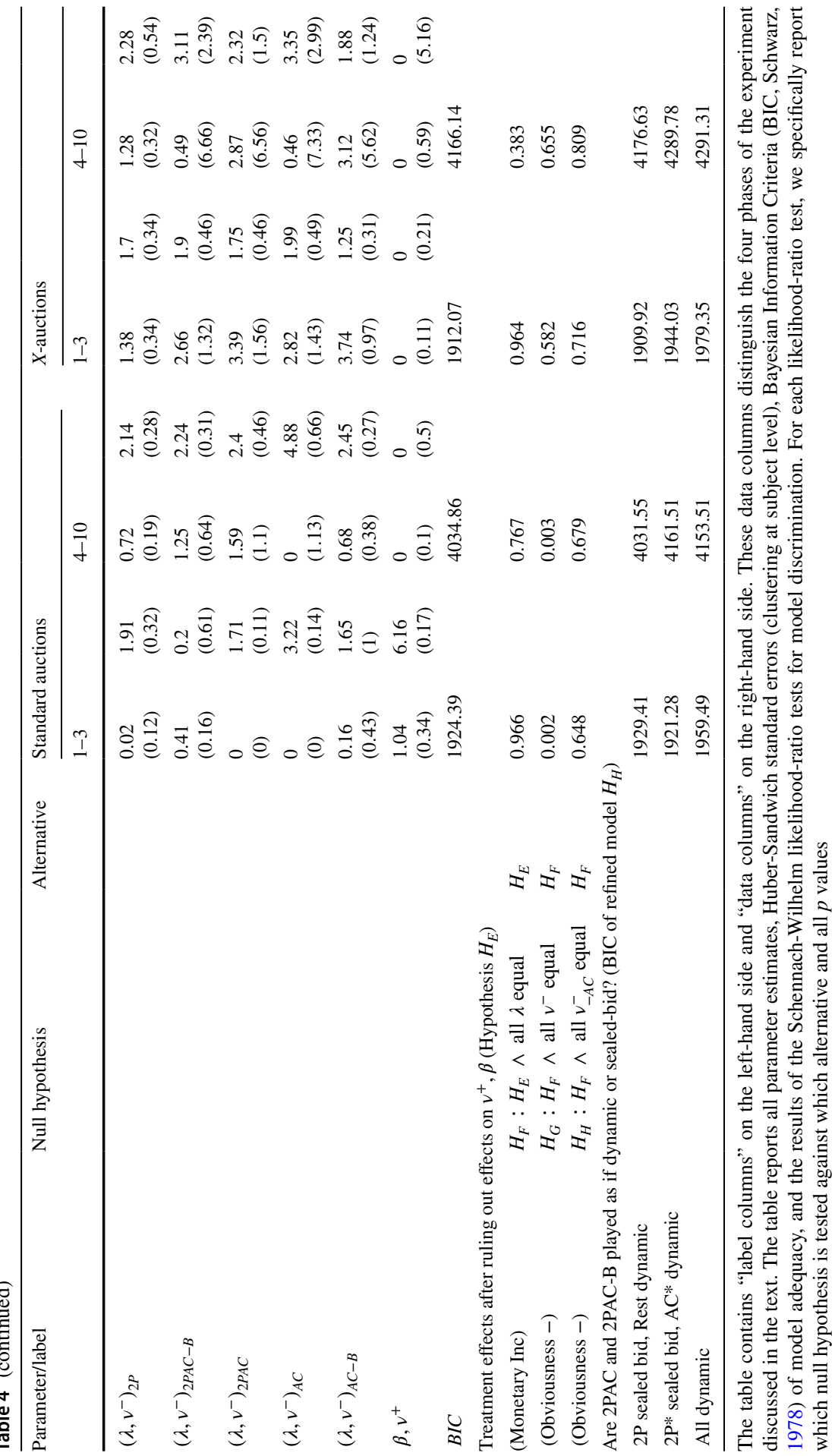


here $\lambda \geq 0$ denotes the weight of monetary incentives in decision making. The probability that the subject ends up bidding $a \in A$ is ${ }^{17}$

$$
\operatorname{Pr}(a)=\left(1-\operatorname{Pr}_{\text {cont }}(a)\right) \cdot \prod_{a^{\prime}<a} \operatorname{Pr}_{\text {cont }}\left(a^{\prime}\right) .
$$

A subject with a static perspective chooses her bid simply based on expected payoffs, implying

$$
\operatorname{Pr}(a)=\frac{\exp \left\{\lambda \cdot \Pi(a)-v^{-} \cdot I_{a<0}-v^{+} \cdot I_{a>0}\right\}}{\sum_{a^{\prime}} \exp \left\{\lambda \cdot \Pi\left(a^{\prime}\right)-v^{-} \cdot I_{a^{\prime}<0}-v^{+} \cdot I_{a^{\prime}>0}\right\}},
$$

using the same parameters $\left(\lambda, v^{+}, v^{-}\right)$as before. We estimate these parameters by maximum likelihood and then evaluate our statistical hypotheses using the robust likelihood-ratio tests of Schennach and Wilhelm (2017). The Schennach-Wilhelm test is robust to misspecification and arbitrary nesting structures, while allowing us to cluster at the subject level.

The results of this analysis are provided in Table 4. In the upper panel of the table, we report the estimates for the full model and for basic tests of treatment effects, on "Monetary Incentives" $(\lambda)$, "Obviousness" $\left(\nu^{-}, \nu^{+}\right)$and "Contingent Reasoning" (exponent $\beta$ in Eq. (4)). We find that treatment differences seem to show up only with respect to obviousness of dominance regarding underbidding $\left(v^{-}\right)$. The respective $p$ values are reported for each test and each phase of the experiment. The second panel then evaluates a refined model that we obtain after ruling out treatment differences in $\nu^{+}$and $\beta$, so we can focus on treatment differences in the weight on monetary incentives $(\lambda)$ and obviousness that underbidding is dominated $\left(v^{-}\right)$. We will focus on the results obtained for this refined model. Let us first summarize the results before we discuss the statistical support.

Result 5 (Behavior in relation to incentives) Initially (rounds 1-3), bidding is not correlated with monetary incentives $(\lambda=0)$. Subsequently:

1. Bidding is significantly correlated with monetary incentives in all formats $(\lambda>0)$, without significant differences between formats.

2. Bidding is dynamic in all formats featuring a price clock, including $2 P A C$ and $2 P A C-B$. It is static only in $2 P$.

3. Bidders evaluate incentives unconditionally $(\beta=0)$ in all formats, including $A C$ and $A C-B$.

4. In all formats, dominance is recognized only regarding underbidding, not overbidding $\left(v^{-}>v^{+} \approx 0\right)$.

5. There are no significant differences between formats in the extent to which subjects recognize dominance, with the sole exception of $A C$ 's standard auctions,

\footnotetext{
17 For simplicity, our specification assumes that a bidder does not take into account the randomness at subsequent increments.
} 
where dominance regarding underbidding is recognized significantly better than in the others.

Point 1 reviews the estimates of the weight on monetary incentives, $\lambda$, which is zero initially and then increases substantially. In Table 4, the lines labeled "(Monetary Inc)" report the $p$ values of tests for significance of differences in $\lambda$ between treatments. The $p$ values are always above 0.3 and mostly even above 0.7 , showing that differences are statistically minor. That is, winning an additional Euro is considered similarly valuable across treatments, and in this sense subjects are similarly rational in all conditions.

Point 2 summarizes the results reported in the bottom panel of Table 4. We say that bidding in a format is static if it is best explained by static expected payoffs, Eq. (6), and we say that bidding is dynamic if it is best explained by incentives under the incremental choice process in Eq. (5). The bottom panel evaluates the hypothesis that only $2 \mathrm{P}$ is played as static against two alternatives: either that bidding is static in all formally static formats (2P, 2PAC and 2PAC-B, summarized as " $2 \mathrm{P}^{*}$ ") and dynamic in both dynamic ones, or that bidding is dynamic in all formats. The results are fairly clear-cut: Aside from the first three auctions, where monetary incentives bear no weight in any treatment $(\lambda=0)$, the differences in the Bayesian Information Criterion (BIC) are substantial in all phases of the experiment.

Point 3 follows immediately from the fact that $\beta=0$ is estimated in all phases of the experiment where monetary incentives carry positive weight (i.e., after round 3). It means that subjects fail to update winning probabilities as they increase their own bid, even in the dynamic auctions. In Fig. 3, we can directly see the main implication of it: Conditional on overbidding in AC auctions, we observe a rather flat, uniform distribution in both our AC treatment and Li's. That is, once subjects move above their values, they seem to believe in a low probability of winning the auction with the next bid increment; otherwise, they would face strong incentives to exit, as shown in Fig. 5.

Point 4 follows from the observation that the weight $v^{+}$, which captures the extent to which subjects account for overbidding being dominated in excess of the payoff difference, does not differ between treatments and is estimated to be zero after round 3. The underlying statistical test is reported in line "(Obviousness +$)$ " in the top panel of the table. In turn, the estimates for $v^{-}$are generally positive and large in relation to their standard errors.

Point 5 follows from the observation that the corresponding weights for underbidding, $v^{-}$, differ highly significantly between treatments in "standard" auctionsalthough there are no differences between auction designs other than AC. The results ( $p$ values) of the underlying statistical tests are reported in the two lines "(Obviousness -)" in the middle panel of the table (with $v_{-A C}^{-}$the vector of all $v^{-}$excluding $\mathrm{AC})$.

Discussion The structural analysis, Result 5, offers a specific explanation of the differences in behavior between $\mathrm{AC}$ and $2 \mathrm{P}$ auctions. After an initial learning 
phase of three auctions, where underbidding is prevalent, subjects understand better that underbidding is dominated than that overbidding is dominated, quantified as $v^{-}>v^{+}$. Considering that expected payoffs are rather symmetric around truthful bidding, see Fig. 5, this implies that subjects will tend to overbid when they approach bidding from a static perspective, Eq. (6). This is the case only for plain $2 \mathrm{P}$ auctions, however. Subjects approach all other auctions, including 2PAC and 2PAC-B, from a dynamic perspective. That is, presentation with the ascending clock instils an iterative reasoning process, where subjects iterate through possible bids in ascending order, even when bidding itself is ultimately static. Similarly to $2 \mathrm{P}$ auctions, also in these other auctions subjects understand dominance better with regards to underbidding $\left(v^{-}>0\right)$ than overbidding $\left(v^{+} \approx 0\right)$, but there is a substantial difference: Walking through multiple prices/bids below one's value in ascending order mechanically implies the observed bias toward underbidding, given that choice is stochastic. $^{18}$

We observe that dominance as such statistically affects behavior, and contrary to monetary incentives, it does so from the very start of the experiment. Further, its effect is stronger in AC than in the other formats, as the $v^{-}$differ. However, we observe this difference only for the dominatedness of underbidding, not overbidding, not for the unfamiliar X-auctions, and not for the other format in which dominance should be obvious as well (AC-B). Thus, overall, the structural analysis confirms our earlier basic results by indicating that theoretical obviousness of dominance does not robustly help predicting when dominated actions are avoided by subjects.

\section{Conclusion}

Li's theory of obvious dominance is a remarkable novel approach towards formally grasping game cognition based only on game-theoretic primitives. The theory's prediction is that any OSP mechanism produces significantly less deviations from dominance play than any SP mechanism that is not OSP. By its nature, there is no single way of testing this prediction, but our study permits a both cleaner and stronger test than existing evidence. Contrary to earlier conclusions based on the joint effect of changing multiple design features at once, we find that, quantitatively, the theory's prediction does not survive our stronger test that varies basic design features one by one and identifies the effect of a single key step that theoretically should make dominance obvious.

Specifically, we show that the behavioral difference between $2 \mathrm{P}$ and $\mathrm{AC}$ is almost entirely due to subtle differences in the feedback that participants receive under these formats, rather than the different strategic structure (simultaneous continuous vs. sequential binary). This informs a long-standing puzzle and confirms as well as

\footnotetext{
18 Take the extreme case of purely noisy behavior (uniform randomization), which implies that subjects would very likely exit only few ticks above the starting bid in the AC auction.
} 
quantifies a general intuition already put forward by Kagel et al. (1987). Importantly, OSP here does successfully capture the apparent cognitive simplification afforded by the ascending clock, yet the underlying theory of obviousness goes too far in insisting on actually dynamic implementation, and this finding is also well in line with the existing evidence on the validity of the widely used strategy method. Our study thereby generally demonstrates the value of behaviorally investigating mechanisms at a fine level of design, especially when it comes to understanding cognition.

Overall, we are led to conclude that the theoretical requirement of obviousness may make dominance even more obvious to economists trained with this concept, but that this might not be true for most people. Indeed, we believe that the observed behavioral patterns are best interpreted as evidence that people do not look for dominance and therefore do not just see it, irrespective of whether it is theoretically obvious or not, but rather have to discover it via learning from feedback. This learning process is influenced not only by the informational content of feedback, but to a surprisingly large extent also by how that very content is presented. As our structural analysis suggests, different framing can fundamentally alter how people understand and think through their incentives in strategy choice. ${ }^{19}$

Supplementary Information The online version contains supplementary material available at https://doi. org/10.1007/s10683-021-09720-z.

Acknowledgements We thank the editor and two anonymous referees for very helpful and contructive comments, and in addition, we thank Kai Barron, Laura Doval, Erik Eyster, Jana Friedrichsen, Antonia Grohmann, Rustamdjan Hakimov, Ulrich Kamecke, Peter Katuščák, Dorothea Kübler, Johannes Maier, Takeshi Murooka, Matthew Rabin, Simeon Schudy, Peter Schwardmann, Roland Strausz, Georg Weizsäcker, and Sevgi Yuksel, as well as our audiences at HU Berlin, the Center for Interdisciplinary Research Bielefeld, ESA World Meeting 2018, University of Osaka, European Behavioral Economics Meeting 2019, Tinbergen Institute and UC Berkeley Simons Institute for their similarly helpful comments. We gratefully acknowledge financial support by the German Science Foundation (CRC TRR 190 and BR 4648/1).

Funding Open Access funding enabled and organized by Projekt DEAL.

Open Access This article is licensed under a Creative Commons Attribution 4.0 International License, which permits use, sharing, adaptation, distribution and reproduction in any medium or format, as long as you give appropriate credit to the original author(s) and the source, provide a link to the Creative Commons licence, and indicate if changes were made. The images or other third party material in this article are included in the article's Creative Commons licence, unless indicated otherwise in a credit line to the material. If material is not included in the article's Creative Commons licence and your intended use is not permitted by statutory regulation or exceeds the permitted use, you will need to obtain permission directly from the copyright holder. To view a copy of this licence, visit http://creativecommons.org/licen ses/by/4.0/.

\footnotetext{
${ }^{19}$ The large effect of theoretically irrelevant live information on others' behavior in the ascending-clock auction suggests that even in strategy-proof environments, learning by individual agents can also be mutually reinforcing.
} 


\section{References}

Andreoni, J., Che, Y.-K., \& Kim, J. (2007). Asymmetric information about rivals' types in standard auctions: An experiment. Games and Economic Behavior, 59(2), 240-259.

Aseff, J. G. (2004). Learning to play second-price auctions: An experimental study. Economics Letters, 85(2), 279-286.

Ausubel, L. M. (2004). An efficient ascending-bid auction for multiple objects. American Economic Review, 94(5), 1452-1475.

Battalio, R., Samuelson, L., \& van Huyck, J. (2001). Optimization incentives and coordination failure in laboratory stag hunt games. Econometrica, 69(3), 749-764.

Brandts, J., \& Charness, G. (2011). The strategy versus the direct-response method: A first survey of experimental comparisons. Experimental Economics, 14(3), 375-398.

Breitmoser, Y. (2021). Controlling for presentation effects in choice. Quantitative Economics, 12(1), 251-281.

Cason, T. N., \& Plott, C. R. (2014). Misconceptions and game form recognition: Challenges to theories of revealed preference and framing. Journal of Political Economy, 122(6), 1235-1270.

Charness, G., \& Levin, D. (2009). The origin of the winner's curse: A laboratory study. American Economic Journal: Microeconomics, 1(1), 207-36.

Cooper, D. J., \& Fang, H. (2008). Understanding overbidding in second price auctions: An experimental study. Economic Journal, 118(532), 1572-1595.

Crawford, V. P., \& Iriberri, N. (2007). Level-k auctions: Can a nonequilibrium model of strategic thinking explain the winner's curse and overbidding in private-value auctions? Econometrica, 75(6), 1721-1770.

Dreyfuss, B., Heffetz, O. \& Rabin, M. (2019). Expectations-based loss aversion may help explain seemingly dominated choices in strategy-proof mechanisms. Working paper, available at SSRN: https:// ssrn.com/abstract=3381244.

Elmes, S., \& Reny, P. J. (1994). On the strategic equivalence of extensive form games. Journal of Economic Theory, 62, 1-23.

Esponda, I., \& Vespa, E. (2014). Hypothetical thinking and information extraction in the laboratory. American Economic Journal: Microeconomics, 6(4), 180-202.

Esponda, I. \& Vespa, E. (2019). Contingent thinking and the sure-thing principle: Revisiting classic anomalies in the laboratory. Mimeo.

Fischbacher, U. (2007). z-Tree: Zurich toolbox for ready-made economic experiments. Experimental Economics, $10(2), 171-178$.

Garratt, R. J., Walker, M., \& Wooders, J. (2012). Behavior in second-price auctions by highly experienced eBay buyers and sellers. Experimental Economics, 15(1), 44-57.

Georganas, S., Levin, D., \& McGee, P. (2017). Optimistic irrationality and overbidding in private value auctions. Experimental Economics, 20, 772-792.

Georganas, S., \& Nagel, R. (2011). Auctions with toeholds: An experimental study of company takeovers. International Journal of Industrial Organization, 29(1), 34-45.

Glazer, J., \& Rubinstein, A. (1996). An extensive game as a guide for solving a normal game. Journal of Economic Theory, 70(1), 32-42.

Goeree, J. K., Holt, C. A., \& Palfrey, T. R. (2002). Quantal response equilibrium and overbidding in private-value auctions. Journal of Economic Theory, 104(1), 247-272.

Goeree, J. K., Holt, C. A., \& Palfrey, T. R. (2008). Quantal response equilibria. In S. N. Durlauf \& L. E. Blume (Eds.), The New Palgrave dictionary of economics. London: Palgrave Macmillan.

Greiner, B. (2015). Subject pool recruitment procedures: Organizing experiments with ORSEE. Journal of the Economic Science Association, 1(1), 114-125.

Güth, W., Ivanova-Stenzel, R., Königstein, M., \& Strobel, M. (2003). Learning to bid: An experimental study of bid function adjustments in auctions and fair division games. The Economic Journal, 113(487), 477-494.

Harrison, G. W. (1989). Theory and misbehavior of first-price auctions. American Economic Review, 79(4), 749-62.

Harstad, R. M. (2000). Dominant strategy adoption and bidders' experience with pricing rules. Experimental Economics, 3(3), 261-280.

Hassidim, A., Romm, A., \& Shorrer, R. I. (2018). 'Strategic' behavior in a strategy-proof environment. Working paper, available at SSRN: https://ssrn.com/abstract=2784659. 
Huck, S., Rasul, I., \& Shephard, A. (2015). Comparing charitable fundraising schemes: Evidence from a natural field experiment and a structural model. American Economic Journal: Economic Policy, $7(2), 326-69$.

Kagel, J. H., Harstad, R. M., \& Levin, D. (1987). Information impact and allocation rules in auctions with affiliated private values: A laboratory study. Econometrica, 55(6), 1275-1304.

Kagel, J. H., \& Levin, D. (1993). Independent private value auctions: Bidder behaviour in first-, secondand third-price auctions with varying numbers of bidders. Economic Journal, 103(419), 868-879.

Kagel, J. H., \& Levin, D. (2009). Implementing efficient multi-object auction institutions: An experimental study of the performance of boundedly rational agents. Games and Economic Behavior, 66(1), 221-237.

Kagel, J. H., \& Levin, D. (2015). Auctions: A survey of experimental research. In J. H. Kagel \& A. E. Roth (Eds.), The Handbook of Experimental Economics, Vol. 2, chapter 9. Princeton: Princeton University Press.

Kirchkamp, O., \& Reiß, J. P. (2019). Heterogeneous bids in auctions with rational and boundedly rational bidders: Theory and experiment. International Journal of Game Theory, 48, 1001-1031.

Li, S. (2017). Obviously strategy-proof mechanisms. American Economic Review, 107(11), 3257-3287.

List, J. A., \& Shogren, J. F. (1999). Price information and bidding behavior in repeated second-price auctions. American Journal of Agricultural Economics, 81(4), 942-949.

Martínez-Marquina, A., Niederle, M., \& Vespa, E. (2019). Failures in contingent reasoning: The role of uncertainty. American Economic Review, 109(10), 3437-3474.

McGee, P., \& Levin, D. (2019). How obvious is the dominant strategy in an English auction? experimental evidence. Journal of Economic Behavior \& Organization, 159, 355-365.

McKelvey, R. D., \& Palfrey, T. R. (1995). Quantal response equilibria for normal form games. Games and Economic Behavior, 10(1), 6-38.

McKelvey, R. D., \& Palfrey, T. R. (1998). Quantal response equilibria for extensive form games. Experimental Economics, 1(1), 9-41.

Noussair, C., Robin, S., \& Ruffieux, B. (2004). Revealing consumers' willingness-to-pay: A comparison of the BDM mechanism and the Vickrey auction. Journal of Economic Psychology, 25(6), 725-741.

Pycia, M. \& Troyan, P. (2019). A theory of simplicity in games and mechanism design. Mimeo.

Rapoport, A. (1997). Order of play in strategically equivalent games in extensive form. International Journal of Game Theory, 26, 113-136.

Rees-Jones, A. (2018). Suboptimal behavior in strategy-proof mechanisms: Evidence from the residency match. Games and Economic Behavior, 108, 317-330.

Roth, A. E., \& Ockenfels, A. (2002). Last-minute bidding and the rules for ending second-price auctions: Evidence from eBay and Amazon auctions on the internet. American Economic Review, 92(4), 1093-1103.

Schennach, S. M., \& Wilhelm, D. (2017). A simple parametric model selection test. Journal of the American Statistical Association, 112(520), 1663-1674.

Schneider, M., \& Porter, D. (2020). Effects of experience, choice architecture, and cognitive reflection in strategy-proof mechanisms. Journal of Economic Behavior \& Organization, 171, 361-377.

Schotter, A., Weigelt, K., \& Wilson, C. (1994). A laboratory investigation of multiperson rationality and presentation effects. Games and Economic Behavior, 6, 445-468.

Schwarz, G. (1978). Estimating the dimension of a model. The Annals of Statistics, 6(2), 461-464.

Thompson, F. B. (1952). Equivalence of games in extensive form. Research Memorandum RM-759, The Rand Corporation.

Turocy, T. L. (2008). Auction choice for ambiguity-averse sellers facing strategic uncertainty. Games and Economic Behavior, 62(1), 155-179.

von Wangenheim, J. (2017). English versus Vickrey auctions with loss averse bidders. CRC TRR 190 Discussion Paper No. 48.

Zhang, L., \& Levin, D. (2017). Bounded rationality and robust mechanism design: An axiomatic approach. American Economic Review: Papers \& Proceedings, 107(5), 235-239.

Publisher's Note Springer Nature remains neutral with regard to jurisdictional claims in published maps and institutional affiliations. 